\title{
Pseudorchomene boreoplebs, a new lysianassid amphipod from Korean waters (Crustacea, Amphipoda, Lysianassoidea)
}

\author{
Tae Won Jung ${ }^{1}$, Charles Oliver Coleman ${ }^{1}$, Seong Myeong Yoon ${ }^{2}$ \\ 1 Museum für Naturkunde Berlin, Leibniz-Institut für Evolutions und Biodiversitätsforschung, Invalidenstraße 43, 10115 Berlin, Germany \\ 2 Department of Biology, Chosun University, Pilmun-daero 309, 16452 Gwangju, Korea
}

http://zoobank.org/3BF8AEA9-F0F5-4B21-9DD1-C716C3142B65

Corresponding author: Seong Myeong Yoon (smyun@chosun.ac.kr)

\begin{abstract}
Received 21 August 2017

Accepted 17 October 2017

Published 1 November 2017

Academic editor:

Danilo Harms

Key Words

Until now, the genus Pseudorchomene Schellenberg, 1926 has been recorded exclusively in Antarctic or sub-Antarctic regions. Pseudorchomene boreoplebs sp. n., described from Korean waters, is the first record from the Northern Hemisphere as well as from temperate regions. This new species is very similar to Pseudorchomene plebs (Hurley, 1965), but can be readily distinguished by its wider basis of gnathopod 1, elongate carpus and angulate anterodistal corner of the propodus on gnathopod 2, having slender setae only on the posterior margin of the carpus on pereopod 5, and lacking posterior lobations of the carpus on pereopods 5-7.
\end{abstract}

Pseudorchomene boreoplebs

amphipod, Korea

lysianassid

new species

taxonomy

\section{Introduction}

Previously, members of the genus Pseudorchomene Schellenberg, 1926 were considered to belong to the complicated 'Orchomene complex' (De Broyer 1984, Barnard and Karaman 1991, Havermans et al. 2010), but the genus Pseudorchomene seems to be well defined as a monophyletic clade by the homogeneity between molecular sequence data of partial COI as well as morphological characters including a triangular or adz-shaped coxa 1 (d'Udekem d'Acoz and Havermans 2012). Hitherto, the genus Pseudorchomene consists of five valid species known from Antarctic or subAntarctic regions by several taxonomic or ecological studies: Pseudorchomene coatsi (Chilton, 1912) from the Weddell Sea, Davis Sea, and South Georgia (Chilton 1912, Schellenberg 1926, Barnard 1932, Lowry and Stoddart 1983, Nyssen et al. 2005, De Broyer et al. 2007, Havermans et al. 2010, d'Udekem d'Acoz and Havermans
2012); Pseudorchomene debroyeri d'Udekem d'Acoz \& Havermans, 2012 from the Falkland Islands and the Kerguelen Islands (De Broyer 1983, d'Udekem d'Acoz and Havermans 2012); Pseudorchomene lophorachis d'Udekem d'Acoz \& Havermans, 2012 from the Scotia Sea and the Weddell Sea (d'Udekem d'Acoz and Havermans 2012); Pseudorchomene plebs (Hurley, 1965) from around the Antarctic (Hurley 1965, De Broyer 1983, Takeuchi et al. 2001, Nyssen et al. 2005, De Broyer et al. 2007, d'Udekem d'Acoz and Havermans 2012); and Pseudorchomene rossi (Walker, 1903) with a circum-Antarctic distribution (Walker 1903, Schellenberg 1926, De Broyer et al. 2007, d'Udekem d'Acoz and Havermans 2012).

In this study, the genus Pseudorchomene is recorded for the first time from the Northern Hemisphere, in Korean waters, with the description of Pseudorchomene boreoplebs sp. n. A key to all known species of the genus Pseudorchomene is also provided. 


\section{Material and methods}

The collected specimens of lysianassids were initially fixed in $80 \%$ ethyl alcohol in the field and then preserved in $95 \%$ ethyl alcohol after sorting in the laboratory. Specimens were stained with lignin pink before dissection. Their appendages were dissected in petri dishes or excavated microscopic slides filled with mixed solution of glycerol-ethanol using dissecting forceps and needles under a stereomicroscope (Leica M205), and mounted onto temporary slides using glycerol. To prepare illustrations, pencil drawings were made under a light microscope (Leica DMLB) with the aid of a drawing tube. These were then scanned, digitally inked, and arranged on digital plates using the methods described by Coleman (2003, 2009). Examined specimens were deposited in the collection of the National Institute of Biological Resources (NIBR) of Korea.

\section{Systematics}

\section{Lysianassoidea Dana, 1849 \\ Lysianassidae Dana, 1849 \\ Pseudorchomene Schellenberg, 1926}

Korean Name: Gae-gin-pal-yeop-sae-u-sok, new

\section{Pseudorchomene boreoplebs sp. $\mathrm{n}$.}

http://zoobank.org/013A64BF-2A20-4579-AB6B-D691D95BBF76 Figs 1-5

Korean Name: Buk-bang-gae-gin-pal-yeop-sae-u, new

Type locality. Near Daejin Port, Daejin-ri Hyeonnae-myeon Goseong-gun Gangwon-do South Korea. The specimens were collected from fishery nets of this port. According to the statements of fishermen, these nets were brought out within a $5 \mathrm{~km}$ radius from Daejin Port and the nets were deployed in about $1-2 \mathrm{~km}$ depth (The precise coordinates were uncertain).

Material examined. Holotype: female, $27.1 \mathrm{~mm}$ (NIBRIV0000806535), paratypes: two males, 15.5-18.0 mm and two females, 15.9-23.5 mm (NIBRIV0000807159); collected from fishery nets in Daejin Port, 11 Mar 2016, by TW Jung.

Etymology. The composite epithet of the specific name, boreoplebs is a combination of the Latin borealis and the specific name of Pseudorchomene plebs (Hurley, 1965). This name refers to a 'similar species to P. plebs living in the northern region'.

Diagnosis. Eyes red or brown in life. Antenna 2 not reduced in both sexes. Gnathopod 1 stocky; basis largely expanded, $2.1 \times$ as long as wide; palm transverse, convex, margin serrated. Gnathopod 2 carpus $0.7 \times$ as long as basis, $3.5 \times$ as long as wide; propodus $0.4 \times$ as long as carpus, weakly angulated anterodistally. Pereopod 5 coxa wider than long; merus posterior lobe well developed, lined with slender setae only (without robust setae). Uropod 3 inner ramus not reaching distal end of proximal article of outer ramus.

Description of holotype female. Head (Fig. 1B) lateral cephalic lobes rounded, expanded anteriorly; eyes pyriform, large, ommatidea small, red or brown in life.

Antenna 1 (Fig. 1C, D) half as long as antenna 2, as long as head to pereonite 1 combined; peduncular article 1 swollen anteriorly; accessory flagellum 5-articulate; flagellum article 1 distinctly elongate; calceoli absent.

Antenna 2 (Fig. 1E) not reduced, $0.4 \times$ as long as body; peduncular articles moderate; flagellum 36-articulate; calceoli absent.

Upper lip (Fig. 1F) epistome convex in lateral view, not separated from upper lip; upper lip produced downward.

Mandible (Fig. 1G, H) incisor smooth but bearing blunt denticles on both sides; lacinia mobilis present on left side only, narrowly cylindrical (finger-like), nearly slender; three small raker setae present on each left and right mandibles, with an patch of setules between molar process and raker setae; molar process narrow, triturative, with an lateral setigerous crest; palp attached proximal to molar process, 3-articulate, article 2 longest, not expanded, with an oblique row of 24 setae distally, article 3 weakly falcate, $0.7 \times$ as long as article 2 , with 26 setae along medial margin and one group of four setae at apex.

Maxilla 1 (Fig. 2A, B) inner plate narrowing distally, not short, setose, with two plumose setae apically; outer plate with eleven toothed setae apically in 7/4 arrangement; palp bi-articulate, distal article swollen laterodistally, apical margin lined with 13 robust setae and one simple seta.

Maxilla 2 (Fig. 2C) inner plate slender, tapering distally, with one row of simple setae and one row of dentate setae overlapped on mediodistal margin, with one long plumose seta at middle of medial margin; outer plate 1.3 $\times$ as long as inner plate, not narrow, also tapering distally and with two rows of simple and dentate setae on mediodistal margin.

Maxilliped (Fig. 2D, E) inner plate rectangular, with one row of nine plumose setae on medial margin distally, with three nodular setae on apical margin; outer plate well developed, subovoid, somewhat elongate, apex not reaching end of palp article 3, lined with 29 small nodular setae on mediodistal margin and with two elongate nodular setae on apex, with one row of ten surficial setae along medial margin; palp 4-articulate, article 1 wider, article 2 $1.1 \times$ as long as article 1 , lined with many long setae on medial margin, article $30.8 \times$ article 2 , article 4 falcate, half as long as article 3 , with minute setae along medial margin and distal surface, apical seta short.

Pereon. Gnathopod 1 (Fig. 2F, G) stout, subchelate; coxa large, triangular, strongly divergent, rounded ventrally, angulate posteroventrally; basis $0.9 \times$ as long as coxa, $2.1 \times$ as long as wide, anterior margin straight, lined 


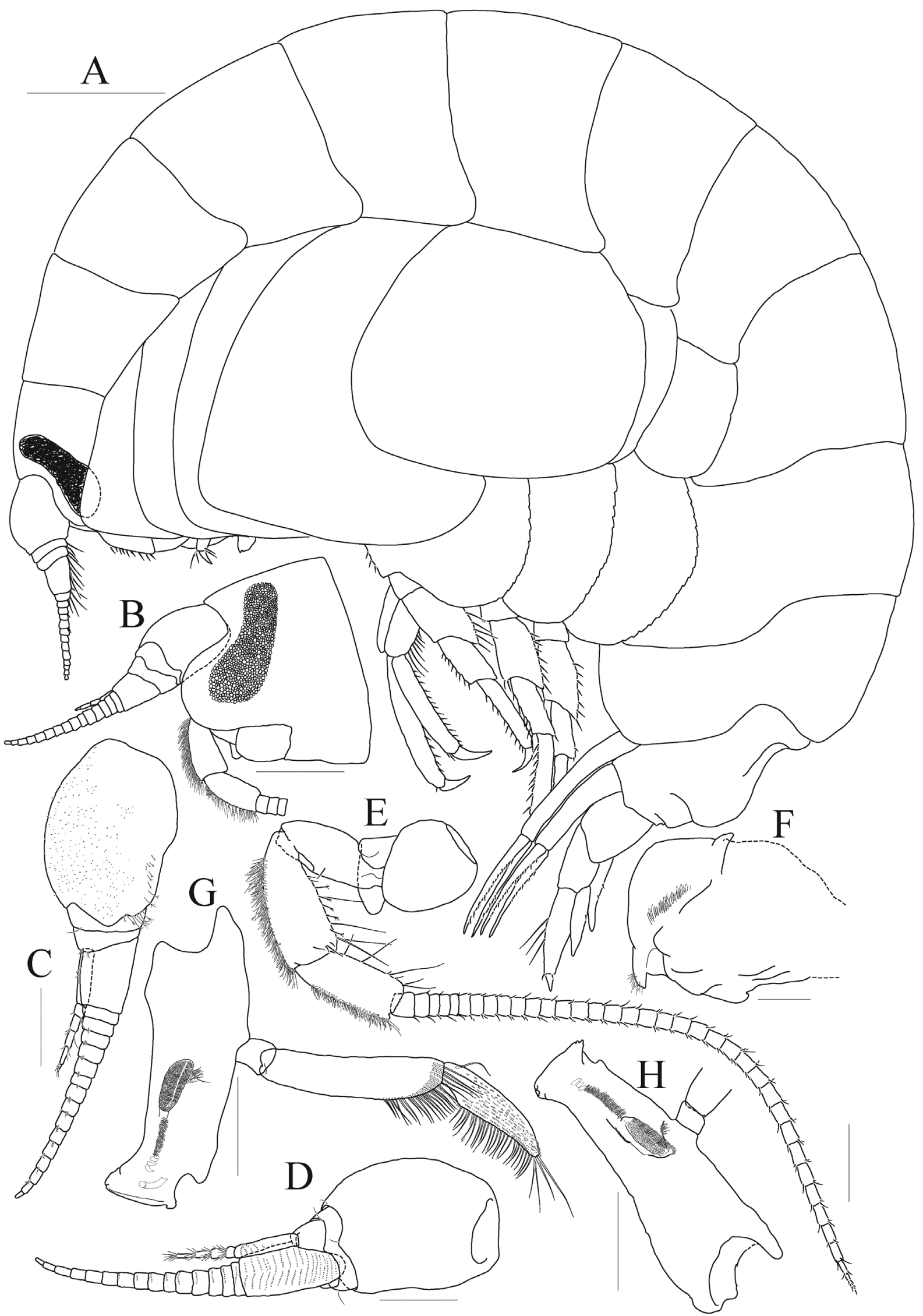

Figure 1. Pseudorchomene boreoplebs sp. n., holotype female $(27.1 \mathrm{~mm})$, NIBRIV0000806535. A habitus; B head; C antenna 1, lateral; D antenna 1, medial; $\mathbf{E}$ antenna 2; $\mathbf{F}$ upper lip, lateral; $\mathbf{G}$ left mandible; $\mathbf{H}$ right mandible. Scale bars $0.2 \mathrm{~mm}(\mathbf{F})$, $0.5 \mathrm{~mm}(\mathbf{C}-\mathbf{E}, \mathbf{G}, \mathbf{H}), 1.0 \mathrm{~mm}(\mathbf{B}), 2.0 \mathrm{~mm}(\mathbf{A})$. 


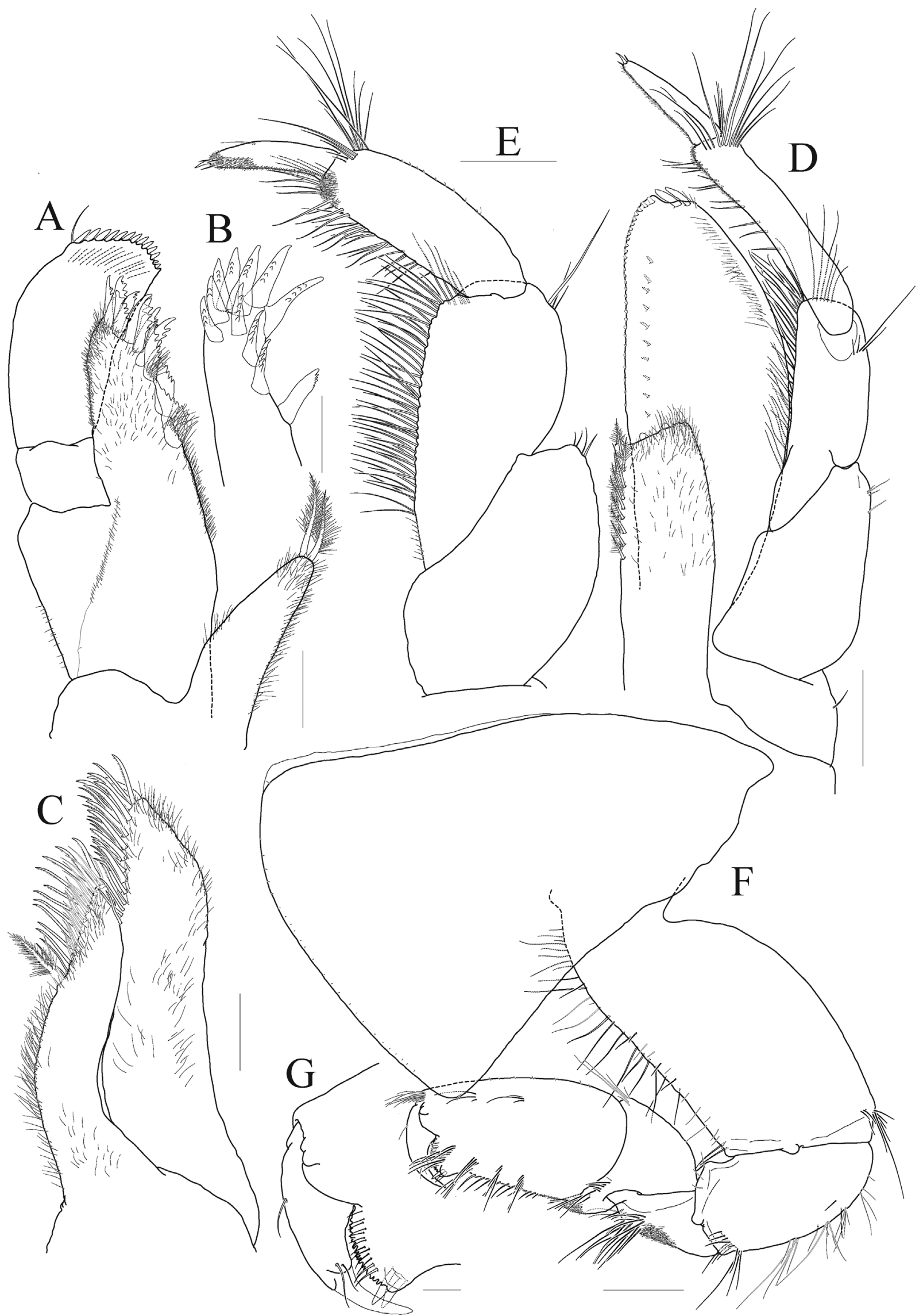

Figure 2. Pseudorchomene boreoplebs sp. n., holotype female $(27.1 \mathrm{~mm})$, NIBRIV0000806535. A maxilla 1; B apical setae on outer plate of maxilla 1; C maxilla 2; D, E maxilliped; F gnathopod 1. Scale bars $0.1 \mathrm{~mm}(\mathbf{G}), 0.2 \mathrm{~mm}(\mathbf{A}-\mathbf{E}), 0.5 \mathrm{~mm}(\mathbf{F})$. 
with slender setae, posterior margin well expanded, only with one group of setae subdistally; ischium half as long as basis; carpal lobe developed; propodus $0.7 \times$ as long as basis, subrectangular, width gradually diminished distally, posterior margin forming weak lobe distally along palm, palm distinct, convex, serrated, with one pair of defining robust setae; dactylus falcate, exceeding palm.

Gnathopod 2 (Fig. 3A-D) slender, minutely chelate; coxa subrectangular, weakly divergent distally, slightly produced posteroventrally; basis linear, as long as coxa, weakly winding at distal $1 / 3$ length, with short setae along anterior and posterior margins; ischium elongate, $0.4 \times$ as long as basis; merus half as long as ischium, covered with short setae posteriorly, with one group of elongate setae at rounded corner posterodistally; carpus $0.7 \times$ as long as basis, $3.5 \times$ as long as wide, anterior margin nearly straight, covered with short setae distally at $2 / 3$ length, with one group of many elongate setae distally, posterior lobe shallow but broad, also covered with minute setae, with one group of elongate setae on mediodistal surface; propodus $0.4 \times$ as long as carpus, slightly expanded distally, densely covered with short setae distally on $2 / 3$ length, anterior margin with several rows of elongate setae distally at half length, forming blunt angle distally, palm distinct but short, weakly produced forward, with one seta near hinge of dactylus and one small protrusion forming cavity bearing one dentate basket, one locking seta located at distal notch; dactylus also short, reaching end of palm, anchored at middle of distal margin of propodus, inner margin weakly serrate distally; oostegite linear, as long as coxa.

Pereopod 3 (Fig. 3E, F) ordinary; coxa subrectangular, $3.0 \times$ as long as wide, slightly curved and produced posteroventrally; basis $0.6 \times$ as long as coxa, subtrapezoidal, somewhat expanded posterodistally, posterior margin with one group of setae distally; ischium, merus, and carpus with many elongate setae posteriorly; ischium elongate, 0.4 $\times$ as long as basis, anterior lobe weak; merus anterior margin expanded, with only one group of setae at anterodistal corner weakly produced; carpus $0.8 \times$ as long as merus, anterior margin slightly convex, without setae; propodus $1.4 \times$ as long as carpus, with seven minute setae anteriorly, posterior margin lined with many paired or triplet robust setae, with one pair of locking setae posterodistally; dactylus falcate, $0.3 \times$ as long as propodus, unguis developed; oostegite linear, $1.2 \times$ as long as that of gnathopod 2 .

Pereopod 4 (Fig. 4A, B) coxa deeper than wide, expanded posteroventrally; other articles and oostegite nearly similar with those of pereopod 3 .

Pereopod 5 (Fig. 4C, D) coxa large, $1.2 \times$ as wide as long, weakly bilobate, anterior and posterior margins not angulate, posterior lobe more expanded downward; basis subovoid, smaller than coxa, slightly wider than long, anterior margin angulate proximally, lined with 27 short setae and with one group of setae distally; posterior lobe largely expanded, rounded, its distal end reaching middle of merus, margin with 15 weak crenellations; ischium short, with a group of setae at anterodistal corner, posterior lobe weak; merus expanded, anterior margin straight, with two robust setae marginally and one group of robust and slender setae distally, posterior lobe well developed, lined with seven slender setae, distal corner produced, with a short seta apically, not exceeding middle of carpus; carpus $0.9 \times$ as long as merus, rectangular, $2.0 \times$ as long as wide, anterior margin lined with robust setae; posterior margin somewhat rounded but not expanded, only with one group of setae distally; propodus $1.8 \times$ as long as carpus, anterior margin lined with many single and paired robust setae, with one pair of locking setae distally, posterior margin only with one group of setae distally; dactylus falcate, $0.3 \times$ as long as propodus, unguis developed; oostegite linear, $0.7 \times$ as long as that of pereopod 4 .

Pereopod 6 (Fig. 4E) $1.1 \times$ as long as pereopod 5; coxa subquadrate, slightly concave anteriorly and convex posteriorly, bilobate, posterior lobe larger and more expanded ventrally, with six minute setae; basis slightly larger than coxa, longer than wide, anterior margin forming weak hump proximally, lined with 15 robust setae, with one group of setae distally, posterior lobe largely expanded, rounded, its distal end slightly exceeding ischium, margin with 15 weak crenellations; ischium anterior margin lined with robust setae marginally and with a group of robust and slender setae distally; merus expanded, anterior margin straight, with ten robust and two slender setae on anterior margin, posterior lobe well developed, distal corner produced, lined with five robust setae; carpus $0.9 \times$ as long as merus, rectangular, $2.2 \times$ as long as wide, anterior margin lined with robust setae, posterior margin somewhat rounded but not expanded, only with one group of setae distally; propodus $1.7 \times$ as long as carpus, anterior margin lined with many paired and triplet robust setae, with one pair of locking setae distally, posterior margin with only one group of setae distally; dactylus falcate, 0.3 $\times$ as long as propodus, unguis developed.

Pereopod 7 (Fig. 4F) $0.9 \times$ as long as pereopod 6; coxa unilobate, oblique anteroventrally; basis larger than that of pereopod 6 , anterior margin forming weak hump proximally and slightly concave distally at $2 / 3$ length, lined with 14 robust setae marginally and with one group of setae distally, posterior lobe largely expanded, rounded, its distal end not exceeding ischium, margin with 24 weak crenellations; ischium anterior margin lined with four robust setae marginally and with one group of robust setae distally; merus expanded, anterior margin straight, lined with ten robust setae irregularly and with one group of setae distally, posterior lobe well developed, with seven robust setae distally on half length, distal corner produced, its end reaching proximal 1/3 length of carpus; carpus 0.8 $\times$ as long as merus, rectangular, $2.0 \times$ as long as wide, anterior margin lined with 15 robust setae irregularly and with one group of robust setae distally, posterior margin somewhat rounded proximally but not expanded, with only one group of setae distally; propodus $1.6 \times$ as long as carpus, anterior margin lined with many paired and triplet robust setae, with one pair of locking setae distally, posterior margin with only one group of setae distally; dactylus falcate, $0.3 \times$ as long as propodus, unguis developed. 


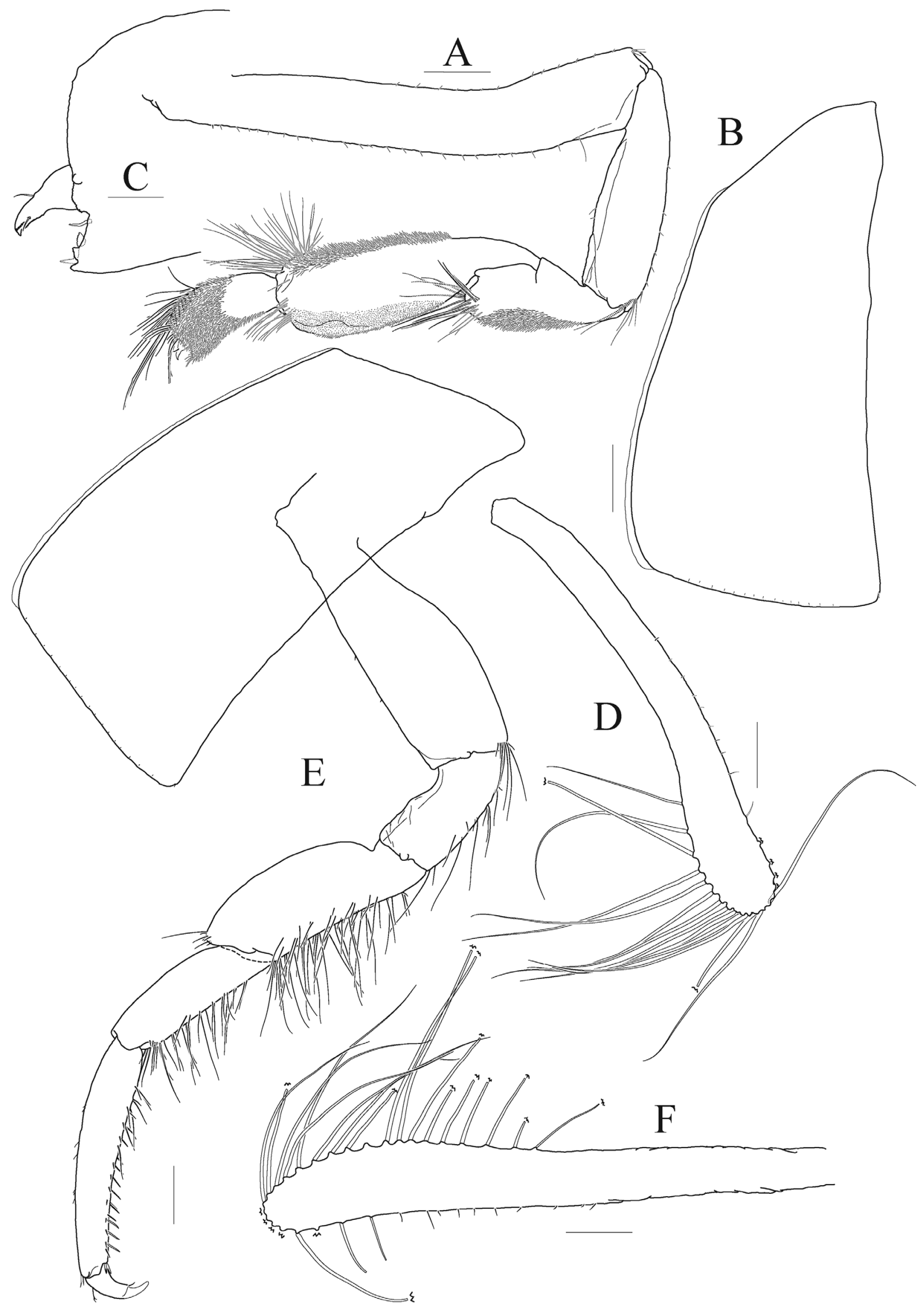

Figure 3. Pseudorchomene boreoplebs sp. n., holotype female (27.1 mm), NIBRIV0000806535. A gnathopod 2; B coxa 2; C palm and dactylus of gnathopod 2; D oostegite of gnathopod 2; E pereopod 3; F oostegite of pereopod 3. Scale bars $0.1 \mathrm{~mm}(\mathbf{C}), 0.5 \mathrm{~mm}$ $(\mathbf{A}, \mathbf{B}, \mathbf{D}-\mathbf{F})$ 


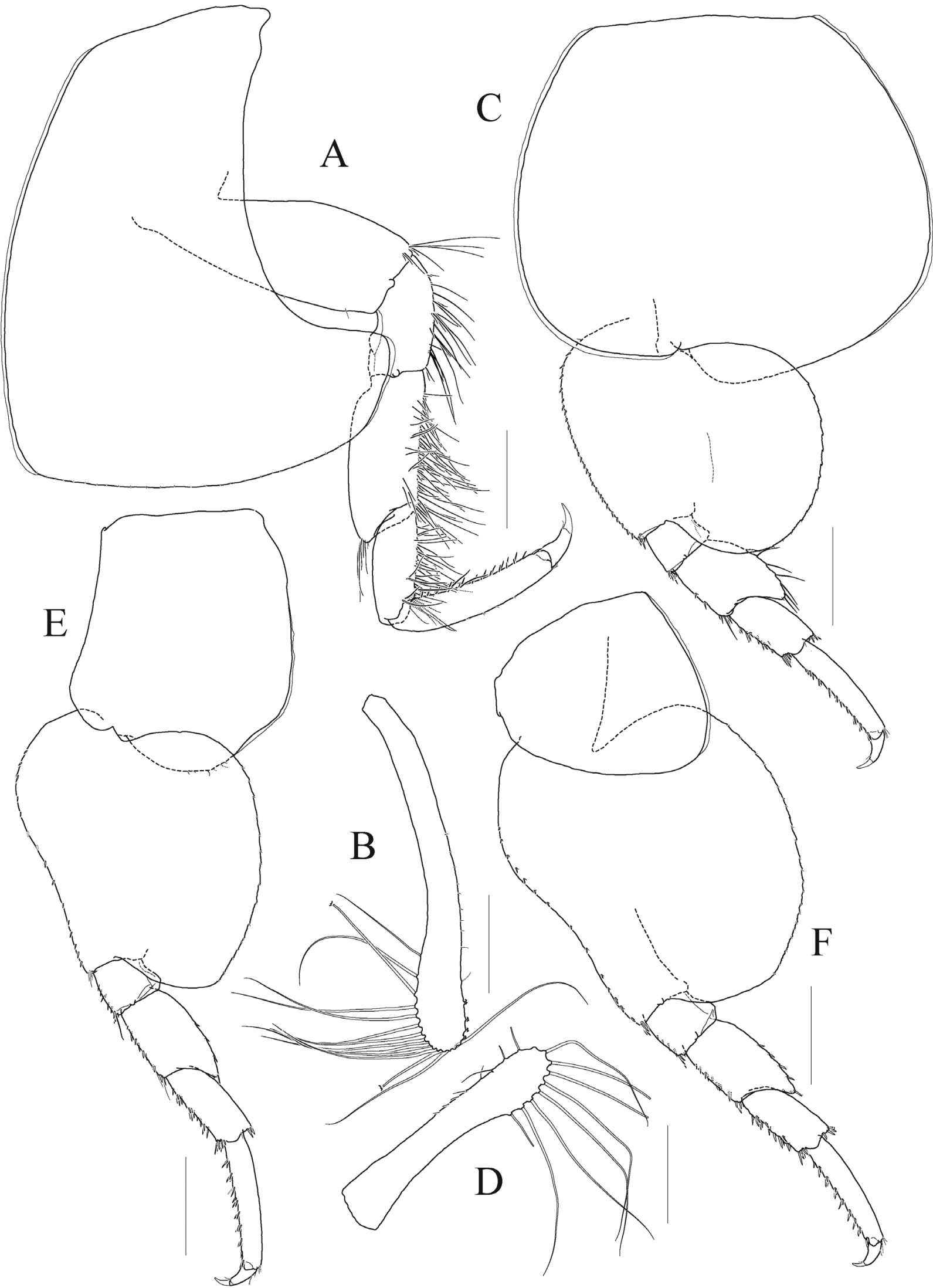

Figure 4. Pseudorchomene boreoplebs sp. n., holotype female $(27.1 \mathrm{~mm})$, NIBRIV0000806535. A pereopod 4; B oostegite of pereopod 4; C pereopod 5; D oostegite of pereopod 5; E pereopod 6; F pereopod 7. Scale bars $1.0 \mathrm{~mm}$ (A-F). 


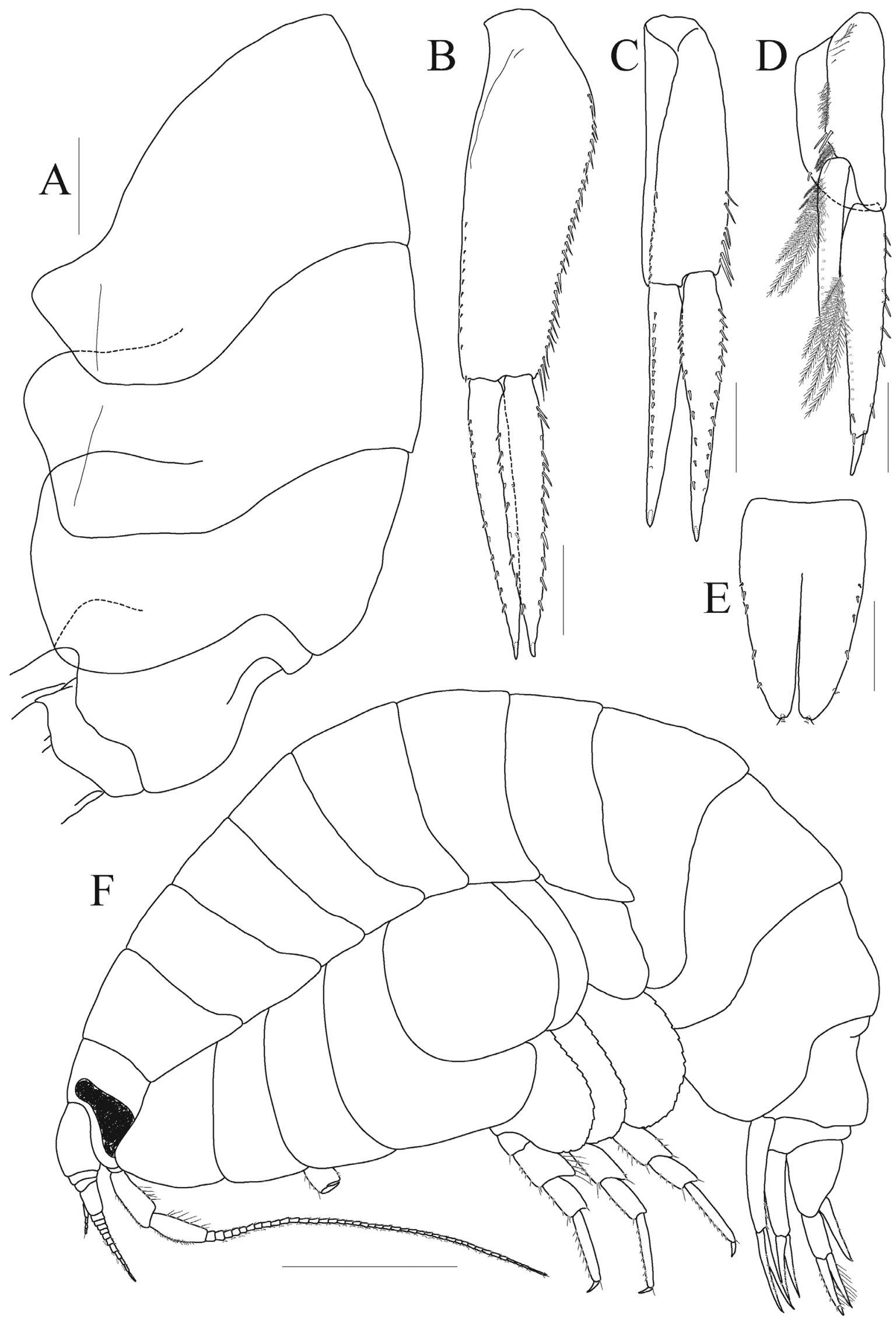

Figure 5. Pseudorchomene boreoplebs sp. n., holotype female (27.1 mm; A-E), NIBRIV0000806535 and paratype male (18 mm; F), NIBRIV0000807159. A pleon, lateral; B uropod 1; C uropod 2; D uropod 3; E telson; F habitus of male. Scale bars $0.5 \mathrm{~mm}(\mathbf{B}-\mathbf{E})$, $1.0 \mathrm{~mm}(\mathbf{A}), 2.0 \mathrm{~mm}(\mathbf{F})$. 
Pleon. Epimeron 1 subquadrate, somewhat produced anteroventrally, ventral margin straight, posterior margin convex, with an oblique ridge on surface. Epimeron 2 larger than epimeron 1 anteroventral corner rounded, weakly produced, ventral margin concave, posteroventral corner subquadrate, with an oblique ridge on surface. Epimeron 3 largest, somewhat expanded antero- and posteroventrally, posterior margin rounded. Urosomite 1 with deep dorsal depression and mid-dorsal carina (Fig. 5A).

Uropod 1 (Fig. 5B) longest; peduncle $1.3 \times$ as long as rami, with twelve short setae (including distal short seta) distally on half of dorsomedial margin and 31 elongate setae along dorsolateral margin; outer ramus almost as long as inner ramus, with 13 lateral and nine medial setae; inner ramus with two lateral and 15 medial short setae.

Uropod 2 (Fig. 5C) $0.8 \times$ as long as uropod 1; peduncle as long as outer ramus, with nine small setae on dorsomedial and seven elongate setae on dorsolateral margin; outer ramus with 14 lateral and ten medial setae; inner ramus $0.9 \times$ as long as outer ramus, with 14 medial setae only.

Uropod 3 (Fig. 5D) $0.8 \times$ as long as uropod 2; peduncle $0.9 \times$ as long as inner ramus; each ramus with plumose setae on medial margin; outer ramus bi-articulate, distal article $0.2 \times$ as long as proximal article; inner ramus 0.8 $\times$ as long as outer ramus, not reaching distal end of proximal article of outer ramus.

Telson (Fig. 5E) $2.0 \times$ as long as wide, cleft to about $70 \%$, each lobe with one weak notch bearing one robust and one simple seta apically and five setae dorsolaterally.

Description of paratype male. Body length between 15.5-18.0 mm, smaller than those of females (15.9-23.5 $\mathrm{mm})$. Not sexually dimorphic in both sexes.

Remarks. Among five valid species of the genus Pseudorchomene, $P$. coatsi, $P$. debroyeri and P. lophorachis are similar to each other in sharing a characteristic gnathopod
1: the convex anterior margin of the basis and the elongate and extremely slender articles from ischium to dactylus (Chilton 1912, d'Udekem d'Acoz and Haverman, 2012). The remaining two species, $P$. plebs and $P$. rossi show a quite different, short and stocky shaped gnathopod 1. Pseudorchomene boreoplebs sp. n. also has a stocky gnathopod 1 , but this new species can be readily distinguished from $P$. rossi by the following differences: 1$)$ the color of the eyes in life is red or brown (vs. black in P. rossi), 2) the basis of gnathopod 1 is more expanded, 3) the coxa of pereopod 5 is wider than that of $P$. rossi and the posterior lobe is more produced downward in P. boreoplebs sp. n., 4) the merus of pereopod 5 is less expanded, it has slender tapering setae posteriorly (vs. robust setae only in P. rossi), and the carpus of pereopod 5 is not expanded posteriorly (vs. expanded posterodistally in P. rossi), 5) the merus and carpus of pereopods 5 and 6 are less or not expanded, 6) the anteroventral corner of pleonal epimeron 1 is more produced, and 7) the apex of the inner ramus on uropod 3 is not reaching the distal end of the outer ramus (vs. subequal in P. rossi) (Walker 1903, d'Udekem d'Acoz and Haverman, 2012). Pseudorchomene boreoplebs sp. $\mathrm{n}$. is quite similar to $P$. plebs, but could be distinguished by the following differences: 1) the distal palp article of maxilla 1 is swollen laterally and has 13 robust setae and one simple seta on apical margin (vs. curved, but not swollen and eight robust setae only in P. plebs, see the Hurley 1965),2) the carpus of gnathopod 2 is 3.5 times as long as wide (vs. 2.6 times as long as wide in $P$. plebs), 3) the propodus on gnathopod 2 is slightly angulate anterodistally (vs. convex anterodistally in P. plebs, see Hurley 1965), 4) the posterior margin of the coxa on pereopod 5 is more convex, wider and not angulate (vs. slightly angulate posteroventrally in P. plebs), 5) the posterior margin of the merus on pereopod 5 has slender setae only (vs. has robust and slender setae in P. plebs), and 6) the anteroventral corner of epimeron 1 is more produced (Hurley 1965, d'Udekem d'Acoz and Haverman, 2012).

\section{Key to known species of the genus Pseudorchomene (modified after d'Udekem d'Acoz and Havermans 2012)}

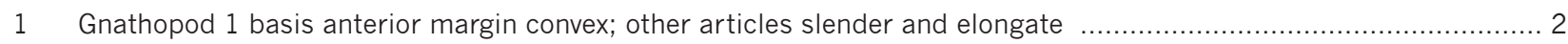

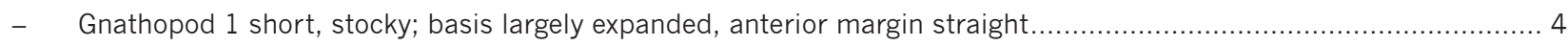

2 Somites of pereon and pleosome with small posterior humps......

Pseudorchomene lophorachis d'Udekem d'Acoz \& Haverman, 2012

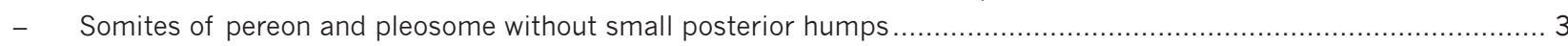

3 Gnathopod 1 palm oblique. Gnathopod 2 carpus $2.3 \times$ as long as wide. Pereopod 7 carpus anterior margin setose mod. erately, posterior margin with posterodistal setae only .............................. Pseudorchomene coatsi (Chilton, 1912) Gnathopod 1 palm transverse. Gnathopod 2 carpus $3.0 \times$ as long as wide. Pereopod 7 carpus anterior margin setose densely, posterior margin and posterodistal corner with setae.......

. Pseudorchomene debroyeri d'Udekem d'Acoz \& Haverman, 2012

4 Eye deep black in life. Pereopod 5 merus of $1.2 \times$ as long as wide, posterior margin with robust setae only. Uropod 3 inner ramus reaching the base of article 2 of outer ramus Pseudorchomene rossi (Walker, 1903)

- $\quad$ Eye red or dark brown in life. Pereopod 5 merus of $1.5 \times$ as long as wide, posterior margin with slender and robust setae or slender setae only. Uropod 3 inner ramus not reaching the base of article 2 of outer ramus ............................ 5

5 Gnathopod 2 carpus $0.5 \times$ as long as basis, $2.6 \times$ as long as wide; propodus convex anteriorly (not angulate anterodistally). Pereopod 5 merus with slender and robust setae .............................. Pseudorchomene plebs (Hurley, 1965)

- Gnathopod 2 carpus $0.7 \times$ as long as basis, $3.6 \times$ as long as wide; propodus weakly angulate anterodistally. Pereopod 5 merus with slender setae only..... . Pseudorchomene boreoplebs sp. n. 


\section{Acknowledgements}

This study was supported by the National Institute of Biological Resources of Korea as a part of the 'Survey of indigenous biological resources of Korea (NIBR NO. 201702-001)' and by the National Marine Biodiversity Institute of Korea as a part of the 'Research for the conservation and management of marine organisms (2017M00100)'.

\section{References}

Barnard KH (1932) Amphipoda. Discovery Reports 5: 1-326. https:// doi.org/10.5962/bhl.part.27664

Barnard JL, Karaman GS (1991) The families and genera of marine gammaridean Amphipoda (Except marine gammaroids). Records of the Australian Museum 13: 1-866. https://doi.org/10.3853 /j.0812-7387.13.1991.91

Coleman CO (2003) "Digital inking": How to make perfect line drawings on computers. Organism, Diversity and Evolution, Electronic Supplement 14: 1-14.

Coleman CO (2009) Drawing setae the digital way. Zoosystematics and Evolution 85(2): 305-310. https://doi.org/10.1002/zoos.200900008

Chilton C (1912) The Amphipoda of the Scottish National Antarctic Expedition. Transactions of the Royal Society of Edinburgh 48(3): 455-520. [pls 1-2]

Dana JD (1849) Synopsis of the genera of Gammaracea. American Journal of Science and Arts, Series 2, 8: 135-140.

De Broyer C (1983) Recherches sur la systématique et l'évolution des crustacés amphipodes gammarides antarctiques et subantarctiques. Thèse de Doctorat en Sciences, Université Catholique de Louvain: 468 pp. [123 pls]

De Broyer C (1984) Evolution du complexe Orchomene Boeck (Amphipoda, Lysianassidae). Annales de la Société Royale Zoologique de Belgique 114(1): 197-198.

De Broyer C, Lowry JK, Jażdżewski K, Robert H (2007) Catalogue of the Gammaridean and Corophiidean Amphipoda (Crustacea) of the Southern Ocean with distribution and ecological data. In: De Broyer
C (Ed.) Census of Antarctic Marine Life: Synopsis of the Amphipoda of the Southern Ocean. Bulletin de l'Institut Royal des Sciences Naturelles de Belgique / Bulletin van het Koninklijk Belgisch Instituut voor Natuurwetenschappen. Biologie 77, Supplement 1, 325 pp.

d'Udekem d'Acoz C, Havermans C (2012) Two new Pseudorchomene species from the Southern Ocean, with phylogenetic remarks on the genus and related species (Crustacea: Amphipoda: Lysianassoidea: Lysianassidae: Tryphosinae). Zootaxa 3310: 1-50.

Havermans C, Nagy ZT, Sonet G, De Broyer C, Martin P (2010) Incongruence between molecular phylogeny and morphological classification in amphipod crustaceans: A case study of Antarctic lysianassoids. Molecular Phylogenetics and Evolution 55: 202-209. https:// doi.org/10.1016/j.ympev.2009.10.025

Hurley DE (1965) A common but hitherto undescribed species of Orchomenella (Crustacea: Amphipoda: Family Lysianassidae) from the Ross Sea. Transactions of the Royal Society of New Zealand 6(11): 107-113.

Nyssen F, Brey T, Dauby P, Graeve M (2005) Trophic position of Antarctic amphipods-enhanced analysis by a 2-dimensional biomarker assay. Marine Ecology Progress Series 300: 135-145. https://doi. org/10.3354/meps300135

Lowry JK, Stoddart HE (1983) The shallow-water gammaridean Amphipoda of the sub-Antarctic islands of New Zealand and Australia: Lysianassoidea. Journal of the Royal Society of New Zealand 13(4): 279-394. https://doi.org/10.1080/03036758.1983.10420804

Schellenberg A (1926) Die Gammariden der Deutschen Südpolar-Expedition 1901-1903. Deutsche Südpolar-Expedition 1901-1903 18(Zool. 10): 235-414.

Takeuchi I, Watanabe K, Tanimura A, Fukuchi M (2001) Assemblages of necrophagous animals off Enderby Land, East Antarctica. Polar Biology 24: 650-656. https://doi.org/10.1007/s003000100264

Watling L (1989) A classification system for crustacean setae based on the homology concept. In: Felgenhauer B, Watling L, Thistle AB (Eds) Functional morphology of feeding and grooming in Crustacea. CRC Press, Rotterdam, 15-26.

Walker AO (1903) Amphipoda of the "Southern Cross" Antarctic Expedition. Journal of the Linnean Society of London, Zoology 29: 38-64. [pls. 7-11] https://doi.org/10.1111/j.1096-3642.1903.tb00425.xw 